\title{
Is It Anaphylaxis or Elder Abuse?
}

\author{
Anaflaksi mi, Yaşlı İstismarı mı?
}

\author{
Müge Gülen', Selen Acehan², Davut Kaplan', Ferhat lçme³, Mustafa Sencer Seğmen', Akkan AvcI \\ 'Department of Emergency Medicine, Eskişehir Yunus Emre State Hospital, Eskişehir, Turkey \\ 2Department of Emergency Medicine, Mersin State Hospital, Mersin, Turkey \\ ${ }^{3}$ Department of Emergency Medicine, Ankara Atatürk Training and Research Hospital, Ankara, Turkey \\ ${ }^{4}$ Department of Emergency Medicine, Kahramanmaraş Necip Fazıl City Hospital, Kahramanmaraş, Turkey \\ ${ }^{5}$ Department of Emergency Medicine, Adana Numune Training and Research Hospital, Adana, Turkey
}

\section{ABSTRACT}

Introduction: Elder abuse and neglect are seen more frequently because of the rapid increase in the elderly population and lack of social security and support systems on account of deteriorating economic conditions.

Case Report: An 80-year-old woman presented to the emergency department on account of swelling and shortness of breath after receiving analgesics. The patient informed that there was no history of trauma. On physical examination, subcutaneous emphysema was noticed; subsequently, computed tomography was performed. Pneumothorax, pneumomediastinum, rib fractures, and parenchymal injury were observed. Bilateral tube thoracostomy was performed and mechanical ventilation was initiated. On questioning the employees of the nursing home where the patient was staying, it was learned that the patient had fallen from the bed. Elder abuse was suspected and the case was reported to the hospital police.

Conclusion: Abuse and neglect of elderly individuals may result in life-threatening consequences. Emergency department physicians should be more careful about the symptoms of abuse during history taking and physical examination.

Keywords: Elder abuse, pneumomediastinum, trauma

Received:03.10.2014 Accepted: 27.11.2014

Available Online Date: 13.02.2015

\section{ÖZET}

Giriş: Yaşlı istismarı ve ihmali, yaşlı nüfusun hızla artması, sosyal güvenlik ve destek sistemlerinin yetersizliği ve kötüleşen ekonomik nedenlere bağlı olarak daha sık görülmektedir.

Olgu Sunumu: 80 yaşında bayan hasta analjezik alımı sonrası vücutta şişlik ve nefes darlığı nedeniyle getirildi. Hastanın travma öyküsü olmadığı söylendi. Fizik muayenede cilt altı amfizemi fark edilen hastaya bilgisayarlı toraks tomografisi çekildi. Hastanın pnömotoraksı, pnömomediastinumu, kot fraktürü ve parankim yaralanması tespit edildi. Hastaya bilateral tüp torakostomi uygulandı ve mekanik ventilatöre bağlandı. Öykü derinleştirilince, hastanın kaldığı bakımevinde yataktan düştüğü kurum çalışanlarından öğrenildi. Hasta yaşlı istismarı olarak değerlendirilip hastane polisine bildirildi.

Sonuç: Yaşlı bireyin istismar ve inmale uğraması yaşamını tehdit eden ölümcül sonuçlara neden olabilir. Acil servis hekimlerinin suistimalin belirtileri konusunda anamnez alırken ve fizik bakı sırasında daha dikkatli olmaları gerekmektedir.

Anahtar Kelimeler: Yaşlı istismarı, pnömomediastinum, travma

Geliş Tarihi: 03.10.2014 Kabul Tarihi: 27.11.2014

Çevrimiçi Yayın Tarihi: 13.02.2015

\section{Giriş}

Yaşam standartlarının gelişmesiyle ülkemizde yaşlı popülasyonu giderek artmaktadır (1). Yaşlı nüfusun hızla artmasıyla, sosyal güvenlik ve destek sistemlerinin yetersizliği ve kötüleşen ekonomik nedenlere bağlı olarak yaşlının istismarı ve ihmali de daha sık görülmektedir (2). Biz bu vakada bakımevinde maruz kaldığı künt toraks travması gizlenen ve bu nedenle tanıda karmaşaya neden olunan nadir ölümcül toraks travmalarından pnömomediastinumlu bir olguyu sunmak istedik.

\section{Olgu Sunumu}

80 yaşında kadın hasta, acil servise analjezik alımı sonrası tüm vücutta şişlik ve nefes alamama şikâyeti ile ambulansla getirildi. Ambulans ekibinden alınan anamneze göre bakımevinde yaşayan hastanın semptomları sırt ağrısı için aldığı analjezik sonrası 
başlamıştı. Ambulansta 20 mg difenhidramin ve 40 mg metilprednizolon intravenöz (IV) uygulandığı öğrenildi. Hasta acil servise getirildiğinde ajite ve şuuru konfüzeydi. Glaskow Koma Skalası: 12 (E4, M5, V3) idi. Vital bulguları; tansiyon arteriyel: $80 / 50$ mmHg, nabı: 120/ dk, vücut ısısı: $36,7^{\circ} \mathrm{C}$, solunum: $35 / d k$, oda havasında oksijen saturasyonu ( $\left.\mathrm{SpO}_{2}\right)$ : \%76 idi. Yatak başı kan şekeri: $113 \mathrm{mg} / \mathrm{dL}$ olarak ölçüldü. Gözlerde bifüssür ödem, boyun ve sırtta ödem, yüzde ve gögüs ön duvarda ciltte hiperemi mevcuttu. Kardiyak muayenede kalp dinlemekle ritmik taşikardikti. Ek ses, üfürüm yoktu. Hasta dispneik, takipneik ve ortopneikti. Bilateral akciğerde ronküsleri ve wheezingi mevcuttu. Batın muayenesinde anormal bulgu saptanmadı. Nörolojik bakıda taraf bulgusuna ve patolojik reflekse rastlanmadı.

Hastanın yakınlarından alınan anamneze göre bilinen ilaç allerjisi, travma öyküsü, sürekli kullandığı ilacı, Alzheimer dışında kronik hastalık öyküsü yoktu. Anamnez ve fizik muayene bulguları birlikte değerlendirildiğinde hastada ilaç alımına bağlı anaflaksi düşünüldü. Hasta acil resüsitasyon odasına alındı. Solunum sistemine ait semptomları da olan hastaya 0,05 mg IV adrenalin yapıldı. Ayrıca 40 mg difenhidramin, $100 \mathrm{mg}$ metilprednizolon ve $100 \mathrm{mg}$ ranitidin IV uygulandı. 10 lt/dk maske ile oksijen ve salbutamol sülfat nebül verildi. Hasta oksijen alırken bakılan arteriyel kan gazında $\mathrm{pH}: 7,21$, $\mathrm{pO}_{2:} 59,7 \mathrm{mmHg}, \mathrm{pCO}_{2}: 44,0 \mathrm{mmHg}, \mathrm{HCO}_{3}: 16,1 \mathrm{mmol} / \mathrm{L}, \mathrm{BE}:-14,9$ $\mathrm{mmol} / \mathrm{L}, \mathrm{SpO}_{2} \% 84,7$ idi. Medikal tedaviyle solunum sıkıntısı rahatlamayan hastanın ödemi üst ekstremitelere ve göğüs ön duvarına doğru artmaya başladı. Hastanın ödemi palpe edildiğinde hissedilen krepitasyonla bunun cilt altı ödem değil cilt altı amfizem olduğu anlaşıldı. Solunum sıkıntısı devam eden, cilt altı ödemi ilerleyen ve şuuru giderek bozulan hasta sedo analjezi eşliğinde uyutularak entübe edildi. Entübasyon sonrasında tüp yeri kontrol edilen hastanın sol akciğerde solunum sesi azalmış olarak duyuldu. Bilgisayarlı toraks tomografisi çekilen hastanın sol akciğerde multipl kot fraktürü, sol akciğerde pnömotoraksı, pnömomediastinumu ve bilateral hemitoraksta yaygın cilt altı amfizemi saptandı (Resim 1). Mekanik ventilatör ihtiyacı olan hastaya öncelikle sol taraftan olmak üzere bilateral tüp torakostomi uygulandı. Tüp torakostomi sonrası çekilen akciğer grafisinde cilt altı dokularda ve kas alanlarında yoğun gaz görüldü. (Resim 2). Hasta yoğun bakıma yatırıldı. Yatışının 2. gününde ekstübe olan hastanın 7. günde tüp torakostomileri çekildi. 10. günde şifa ile taburcu oldu.

Hastanın acil servisteki tedavisi bittiğinde hasta yakınlarından hastanın herhangi bir travmaya maruz kalıp kalmadığının bakım evinden öğrenilmesi istendi. Hastanın ambulansla getirilmeden 2 saat önce yatağından düştüğü öğrenildi. Hasta yaşlı istismarı olarak değerlendirilip adli vaka olarak hastane polisine bildirildi.

\section{Tartışma}

Yaşlanma; her canlı için döllenme ile başlayıp ölüme kadar devam eden biyolojik bir süreçtir (3). Beklenen yaşam süresinin uzaması ve doğurganlığın azalması gibi nedenlerle tüm dünyada yaşlı nüfusun toplam nüfusa oranı giderek artmaktadır (4). Ülkemizde 2013 yılı Türkiye Nüfus ve Sağlık Araştırması sonuçlarına göre, 65 yaş ve üstü nüfus tüm nüfusun \%7,7'sini oluşturmaktadır ve 2023 yılında bu oranının \%10,2'ye ulaşacağı tahmin edilmektedir (5). Yaşlı nüfusundaki

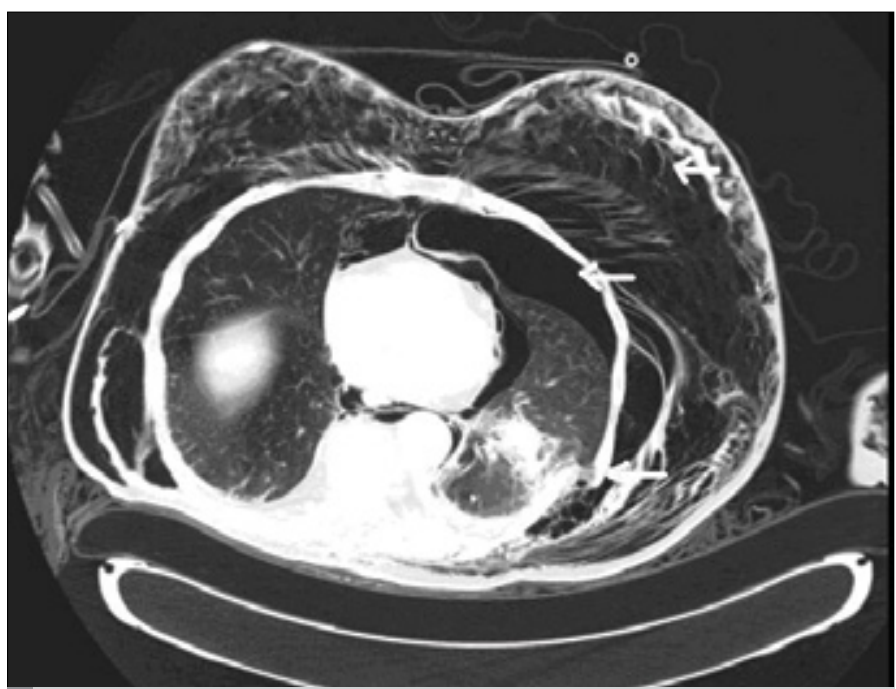

Resim 1. Bilgisayarlı toraks tomagrafisinde; sol hemitoraksta 7. ve 8. Kotlarda belirgin deplasman gösteren fraktür hattı, sol akciğerde parankimal hemoraji, sol hemitoraksta daha belirgin olmak üzere bilateral pnömotoraks, pnömomediastinum ve yaygın cilt altı amfizemin

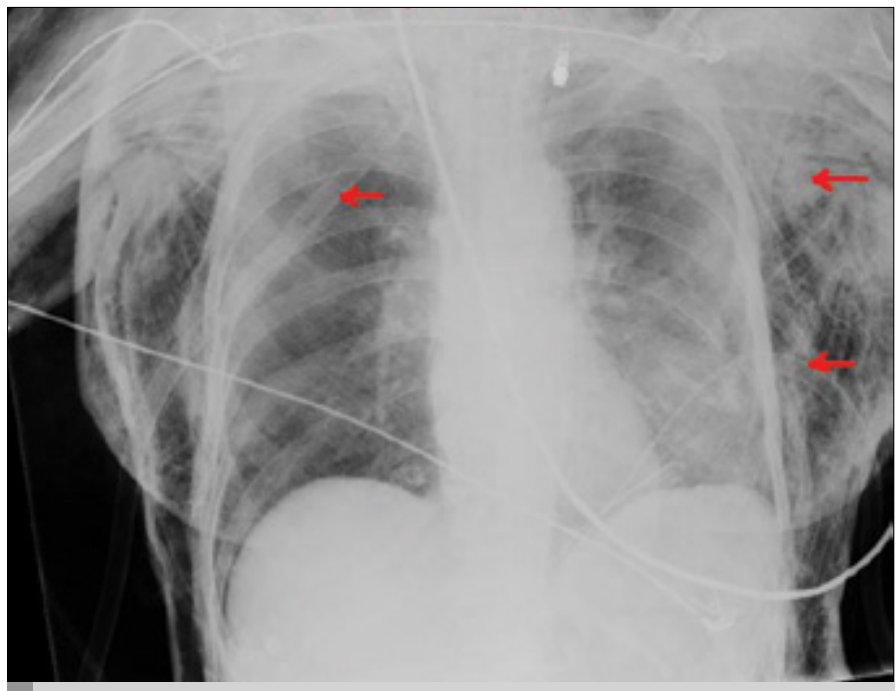

Resim 2. Posterior-anterior akciğer grafisinde cilt altı amfizem görünümü ve bilateral tüp torakostomi uygulaması

bu artış nedeniyle gün geçtikçe yaşlııkla ilgili sorunlarla daha sık karşılaşılması da kaçınılmaz olmuştur (4). Yaşıılık dönemi; bireylerin bağımlılık ve kaza riskinin arttığı, fiziksel yeteneklerinin azaldığı, pek çok kronik hastalığın yaşandığı bir dönemdir (6). Artan bu bağımlılık kişiyi bakımını sağlayan kişi veya kurumların inmali veya istismarına maruz bırakabilmektedir. Genel olarak yaşlı istismarı, yaşlıda maddi ve manevi acı ve yaralanmalara neden olan; inmalin doğmasını sağlayan fiziksel ve psikolojik davranışların bütünü olarak tanımlanmaktadır (7). İstismar her toplumda, her kültürde ve her ekonomik düzeyde görülebilmektedir. Aile içinde, sağlık ve sosyal hizmetlerin verildiği kurumlarda fiziksel ve psikolojik olarak yaşlıya zarar verme ve ondan faydalanma şeklinde kendini gösteren ciddi toplumsal bir sorundur 
(3). Bizim vakamızda da hasta; bakımını üstlenen kurumda bir travmaya maruz kalmıştır. Ancak kurum yetkilileri bunun için hastanın herhangi bir sağlık kurumuna getirilmesini gerekli görmemişlerdir. Ağrısı için hastaya verdikleri analjezik sonrasında olduğunu düşündükleri nefes darlığı ve vücutta şişliğin artması nedeniyle ambulans ekibine haber vermişlerdir. Hastanın travma öyküsünün bakımını veren kişilerce gizlenmesi tanının konulmasını geciktirmiş ve tedaviyi yanlış yönlendirmiştir.

Yaşlı istismar ve ihmali hastaya fiziksel şiddet uygulamak, kişisel bakımını sağlamamak, sağlık hizmetine ulaşmasını engellemek veya ruhsal yönden zarar vermek şeklinde geniş bir yelpazede incelenmelidir. Yaşlı istismar ve ihmalinde en önemli konu problemin farkında olunmaması ya da saptanmasındaki engellerdir. Kişiye direk istismara uğrayıp uğramadığı veya istismarcıyı suçlayıcı yönde sorulacak sorular istismarın saptanmasına engel olabilir. Sağlık çalışanları olarak yaşlı istismar ve ihmalinin önlenebilmesi için bizlere düşen istismarın nedenlerinin, sonuçlarının ve önlenmesinin araştırılmasına katkıda bulunmaktır. Bu ancak anamnez alırken sorulacak soruların doğru seçilmesi, suçlayıcı, yargılayıcı olmaması ve ayrıntılı bir fizik bakı ile mümkündür (3). Anamnez alırken yaralanma oluşumu ve tedavi arama arasında gecikmelerin olması, yaralanmanın ciddiyetinin önemsenmemesi veya inkar edilmesi sağlık personelini istismar açısından uyarıcı olmalıdır. Ayrıca aile üyelerinin ve diğer bakım verenlerin uygunsuz reaksiyonu, anlatılanlarla fizik muayene bulguları arasında uyumsuzluk olması da dikkat çekici diğer bulgulardır. Fizik muayenede fark edilebilecek direk ve indirek istismar bulguları vardı. Yetersiz beslenme ve hidrasyon, hastanın hijyenin sağlanmaması, nedeni açıklanamayan, iyileşmesi geciken ve farklı iyileşme aşamalarındaki kırıklar ve yaralar, ekstremitelerde kontraktürler direk istismar bulgularındandır. Tıbbı tedavilerin gecikmesi, tedavilerin uygun kullanılmayışı, sık sık acile başvurma, tekrarlayan yaralanmalarda aynı sağlık kurumuna gitmeyi reddetme, yaralanma hakkında çelişkili kaçamak ifadeler ve tutumlarda bulunulması inmal ve istismarın indirek bulgularıdır $(3,4)$. Bizim vakamızda anamnez alacak herhangi bir kurum yetkilisi hastaya refakat etmediğinden ve hasta ile de demansı ve solunum sıkıntısı nedeniyle kooperasyon kurulamadığından olayla ilgili kısıtlı bilgi sadece ambulans ekibinden alınabilmiştir. Ambulans ekibine verilen eksik bilgiler ve travma öyküsünün gizlenmesi hastanın tanısının gecikmesine neden olmuştur. Ancak yapılan fizik bakıda palpasyonla cilt altı amfizemin fark edilmesi mevcut kliniğin bir ilaç allerjisi olmadığının anlaşıımasına yardımcı olmuştur.

\section{Sonuç}

Yaşlı bireyin istismar ve ihmale uğraması yaşamını tehdit eden ölümcül sonuçlara neden olabilir. Böylesine kritik durumlarda suistimale maruz kalan bireylerin ilk başvuru yerleri acil servislerdir. Bu nedenle acil servis hekimlerinin suistimalin belirtileri konusunda daha dikkatli olmaları gerekmektedir. Anamnez alırken suçlayıcı, yargılayıcı olma- yan doğru soruların sorulması ve dikkatli bir fizik bakı ihmal ve istismarın tanınmasına yardımcı olacak tanı ve tedaviyi hızlandıracaktır.

Informed Consent: Written informed consent was obtained from the patient and their relatives who participated in this case.

Peer-review: Externally peer-reviewed.

Author Contributions: Concept - M.G., D.K.; Design - M.G., S.A.; Supervision - M.G., F.I.; Materials - M.G., D.K. Data Collection and/or Processing - M.G., D.K.; Analysis and/or Interpretation - M.G., S.A.; Literature Review - M.G., F.l.; Writer - M.G., A.A.; Critical Review - M.G., S.A.

Conflict of Interest: The authors declared no conflict of interest.

Financial Disclosure: The authors declared that this study has received no financial support.

Hasta Onamı: Bu çalışmaya katılan hastadan ve yakınlarından hasta onamı alınmıştır.

Hakem değerlendirmesi: Dış bağımsız.

Yazar Katkıları: Fikir - M.G., D.K.; Tasarım - M.G., S.A.; Denetleme - M.G., F.l.; Malzemeler - M.G., D.K.; Veri toplanması ve/veya işlemesi - M.G., D.K.; Analiz ve/veya yorum - M.G., S.A.; Literatür taraması - M.G., F.l.; Yazıyı yazan - M.G., A.A.; Eleştirel İnceleme - M.G., S.A.

Çıkar Çatışması: Yazarlar çıkar çatışması bildirmemişlerdir.

Finansal Destek: Yazarlar bu çalışma için finansal destek almadıklarını beyan etmişlerdir.

\section{Kaynaklar}

1. Güneytepe Üil, Aydın ŞA, Gökgöz Ş, Özgüç H, Ocakoğlu G, Aktaş H. Yaşlı travma olgularında mortaliteye etki eden faktörler ve skorlama sistemleri. Uludağ Üniversitesi Tıp Fakültesi Dergisi 2008; 34: 15-9.

2. American Psychological Association. Elderly abuse and neglect: in search of solutions. http://www.apa.org/pi/aging/resources/guides/elder-abuse.pdf. (Erişim Tarihi: 25.9.2014)

3. Gülen M, Aktürk A, Acehan S, Seğmen MS, Açıkalın A, Bilen A. Yaşlı istismarı ve ihmali. Arşiv Kaynak Tarama Dergisi 2013; 22: 393-407.

4. Uysal A. Dünyada yaygın bir sorun; yaşlı istismarı ve ihmali. Aile ve Toplum Dergisi 2002; 5: 43-9.

5. Türkiye İstatistik Kurumu, İstatistiklerle Yaşlıar 2013 http://www.tuik. gov.tr/PreHaberBultenleri.do?id=16057 (Erişim Tarihi: 25.10.2014)

6. Koştu N. Yaşlı istismarı ve inmalinin önlenmesinde halk sağlığı hemşiresinin rolü. Özveri Dergisi 2005; 2: 527-34.

7. Alkan N, Fincancı ŞK. Aile içi şiddette adli tıbbın işlevi. I. Ulusal Aile Hizmetleri Sempozyumu. TC Başbakanlık Aile Araştırma Kurumu Bilim Serisi: 117, Ankara. 2001: 149-53. 